\title{
Retrofitting Campus Outdoor Space Based on Thermal Performance: Case Study Seberbay University Campus, Tanta City
}

\author{
Shahira Sharaf Eldin ${ }^{1}$, Mustafa M. Elwan ${ }^{1, *}$, Amr A. Bayoumi ${ }^{2}$ \\ ${ }^{1}$ Faculty of Engineering, Tanta University, Tanta, 31733, Gharbia, Egypt \\ ${ }^{2}$ Arab Academy for Science, Technology \& Maritime Transport, Port Said, 1029, Port Said, Egypt
}

Received February 7, 2021; Revised June 15, 2021; Accepted October 15, 2021

\section{Cite This Paper in the following Citation Styles}

(a): [1] Shahira Sharaf Eldin, Mustafa M. Elwan, Amr A. Bayoumi, "Retrofitting Campus Outdoor Space Based on Thermal Performance: Case Study Seberbay University Campus, Tanta City," Civil Engineering and Architecture, Vol. 9, No. 7, pp. 2505 - 2516, 2021. DOI: 10.13189/cea.2021.090734.

(b): Shahira Sharaf Eldin, Mustafa M. Elwan, Amr A. Bayoumi (2021). Retrofitting Campus Outdoor Space Based on Thermal Performance: Case Study Seberbay University Campus, Tanta City. Civil Engineering and Architecture, 9(7), 2505 - 2516. DOI: 10.13189/cea.2021.090734.

Copyright $\bigcirc 2021$ by authors, all rights reserved. Authors agree that this article remains permanently open access under the terms of the Creative Commons Attribution License 4.0 International License

\begin{abstract}
University campuses are meant to provide open and green spaces for students to create and excel. In this paper, the redesign of the Campus Outdoor Space (COS) of the College of Engineering in Tanta is assessed as it is a central square overlooked by buildings of the college exposed to excessive solar radiation. The method of the study consists of many stages. First, field measurements were appraised by Nova- Lynx weather station and investigating weather data files through the Climate consultant program. Next, the proposed design was tested and evaluated with the simulation programs Ansys Fluent CFD software to investigate thermal conformability. The positive environmental impact of the new design was revealed by comparing contours of solar heat flux, reflected infrared solar flux, wall radiated heat flux of surrounding buildings and analysis of temperature. Results indicated that $\operatorname{COS}$ redesign initiated a framework that integrates environmental comfort approaches producing retrofitting design rubric.
\end{abstract}

Keywords Solar Radiation, Retrofitting Urban Study, Thermal Comfort, Campus Outdoor Spaces

\section{Introduction}

The campus boundary includes all open and closed spaces of the university, where educational, cultural, and social activities are taking place [1]. COS integrate and organize campus elements to facilitate scholars' movement, gathering in a comfortable environment. Plants, shades, fountains, and pavements provide a comfortable microclimate for users $[2,3]$.

COS in Seberbay was exposed to excessive solar radiation, without shaded seating areas or convenient paths. As a result, social contact and comfort environmental retrofitting were the main pillars of the design decisions[4], the retrofitting process began with a general examination of the COS to determine main obstacles. After that, appropriate solutions are suggested and analyzed. Finally, COS before and after implementation of the design elements and guidelines are compared [5].

\subsection{Description of the Existing Conditions of the Campus and Its Surrounding}

The Seberbay campus is located in Tanta, Egypt, with coordinates: $\left(30^{\circ} 49^{\prime} 32.46^{\prime \prime} \mathrm{N}, 30^{\circ} 59^{\prime} 41.4^{\prime \prime} \mathrm{E}\right)$. The campus consists of nine main buildings and some low-rise buildings. The Campus area is $782 \times 240 \mathrm{~m} 2(\mathrm{~L} \times \mathrm{W})$. The buildings have different heights which vary from 10 to 20 $\mathrm{m}$. The campus is surrounded by a flat terrain from three directions (The north, west, and south) that is agricultural land. The eastern direction contains high terrain residential buildings; their height ranges between 10 and $30 \mathrm{~m}$ [6]. 
The aerial view of the campus from Google Earth as shown at the top of figure 1 illustrates the orientation of each building concerning the other. Design processes begin by collecting data, maps, and photos[1], Then, design decisions were based on the evaluation of obtained data and the current situation of the study area. Another aerial view of the campus from Google Earth is shown in the middle of figure 1 which focuses on the study area and the Campus Open Space between the buildings which has been redesigned. The buildings are different in shape. Each one has a specific design, and the distances between adjacent buildings are also different.
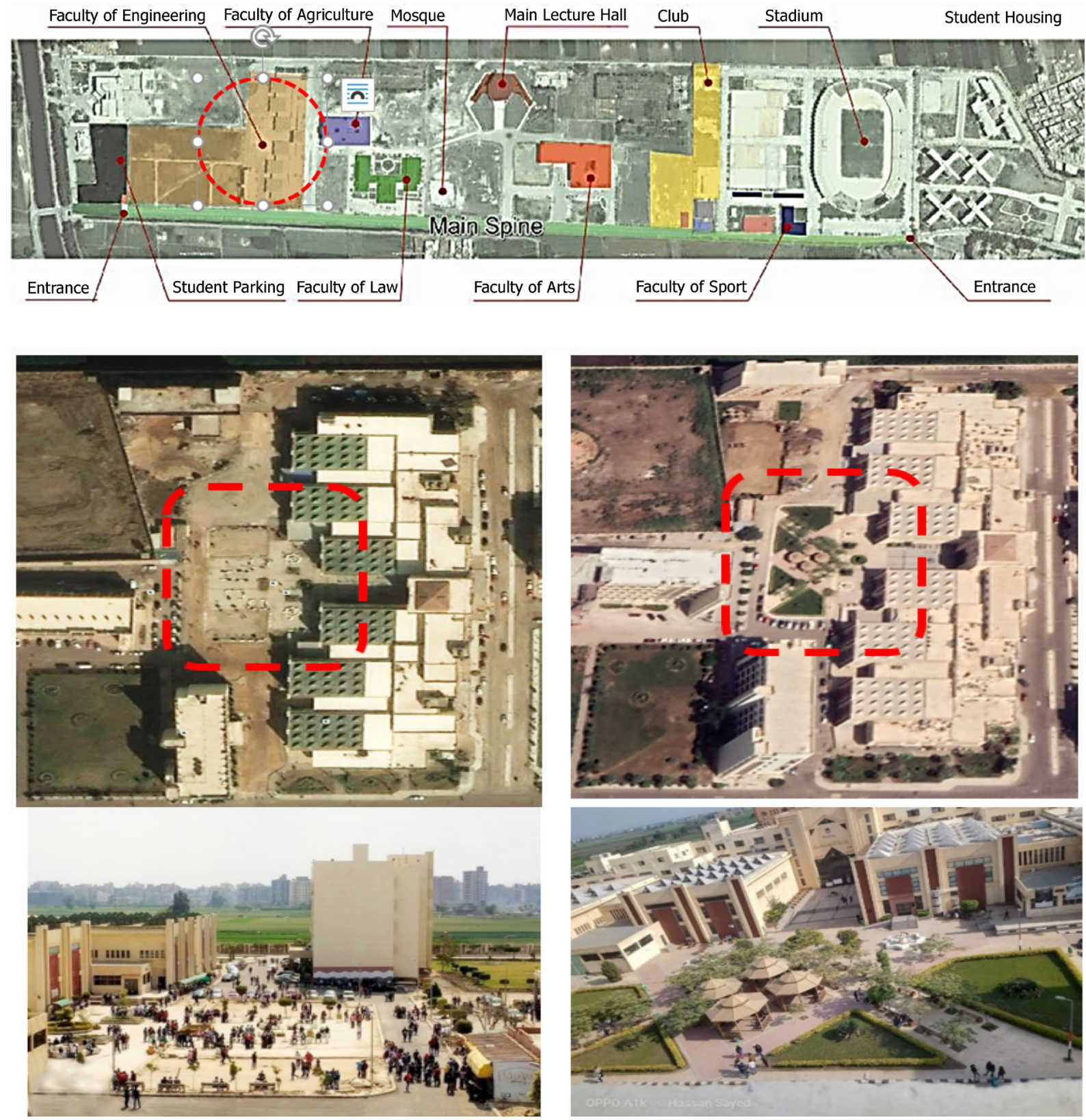

Figure 1. Showing the Seberbay campus and the open space in front of engineering faculty buildings (length $105 \mathrm{~m}$ and width $77 \mathrm{~m}$ ) before and after Campus Outdoor Space design, (Google photos and researchers) 


\subsection{Seberbay Campus' Open Space New Concept Design}

The Campus Outdoor Open Space[7], as shown at the right in Fig.2, can be indicated by eight sides or an octagon shape plaza. The total area of the plaza is $2333 \mathrm{~m} 2$ as measured roughly on the Google Earth map.

In front of the buildings of workshops, seating areas were arranged on both sides of the main entrance. Wooden materials and Islamic design of the seating areas adapted their instalment. Shades from the surrounded buildings created a cooling effect for users. In the middle of the seating areas in front of the main building entrance, some occasional land uses can be observed such as exhibitions and student centre services, as shown in Fig.2.
The new design of the Campus outdoor Space attempted to provide some features like welcoming, attractiveness, smooth accessibility, and safety[1,8,9].

The main COS in front of the buildings was designed almost like the Islamic Mafrouka shape embracing greeneries and pedestrian paths as shown on the left side in Fig. 2. The main target of the design was at protecting COS users from excessive solar radiation and high temperature by setting up semi arched path surrounded by trees and shrubs and establishing shaded seating areas like pergolas Moreover, pedestrian paths were defined by different floor finishing materials. As for educational buildings, they became easy to reach by using shaded pedestrian walkways [1], as shown in Fig.1.
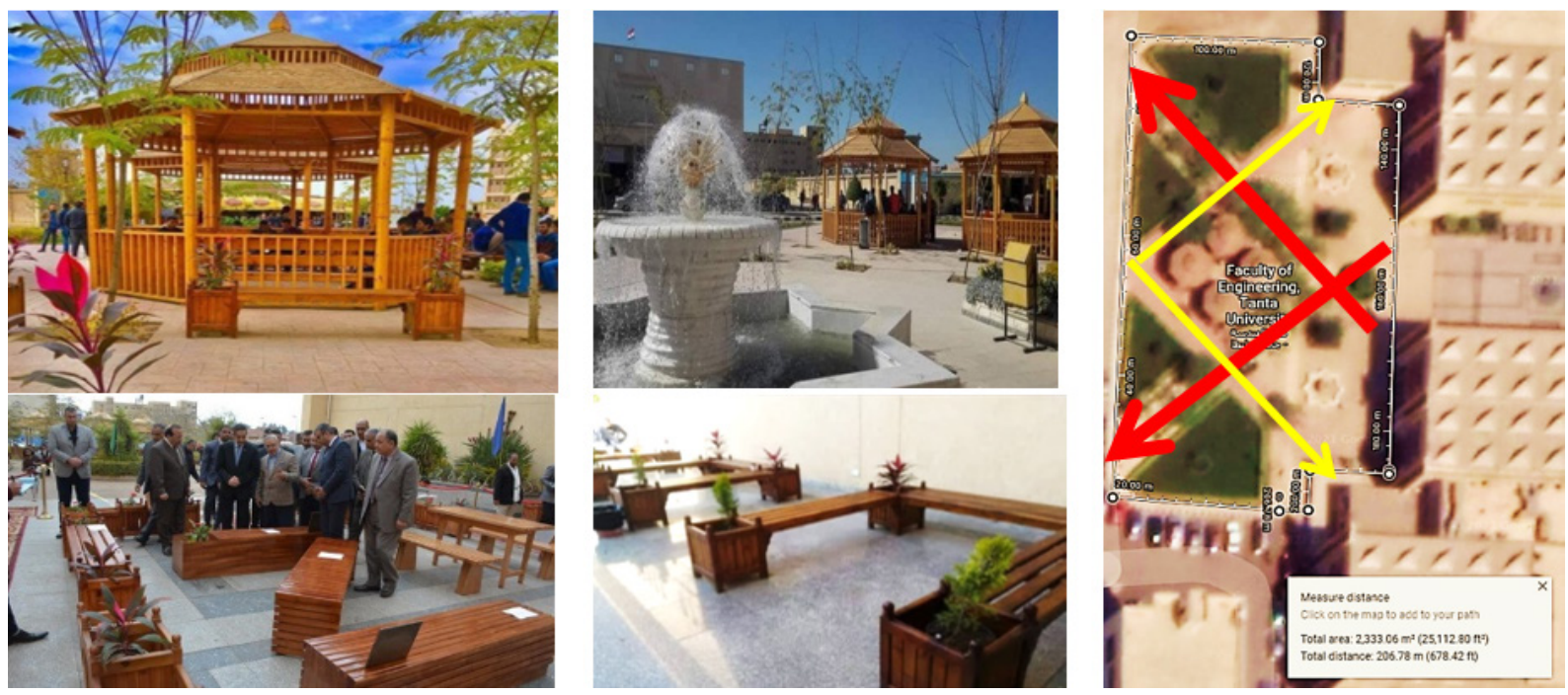

Figure 2. Photos of COS such as the wooden pergolas, The Islamic Design seating areas, the fountain (left) (Source: Google photos) and Google Earth map of the studied plaza, and its boundaries displaying pedestrian circulation pattern (on the right)

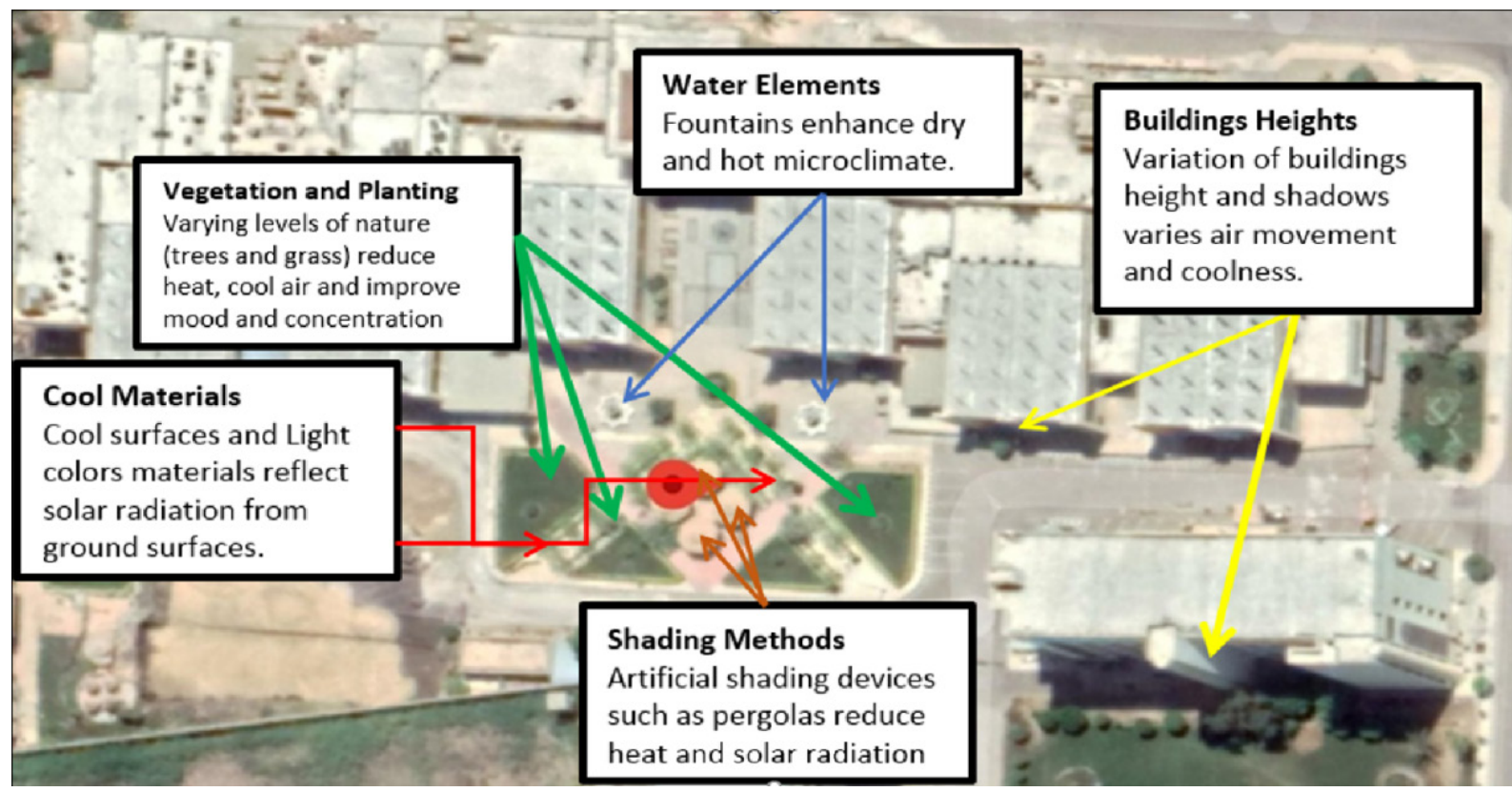

Figure 3. Microclimate intervention enhancing hot dry urban environments, (Source: Authors) 

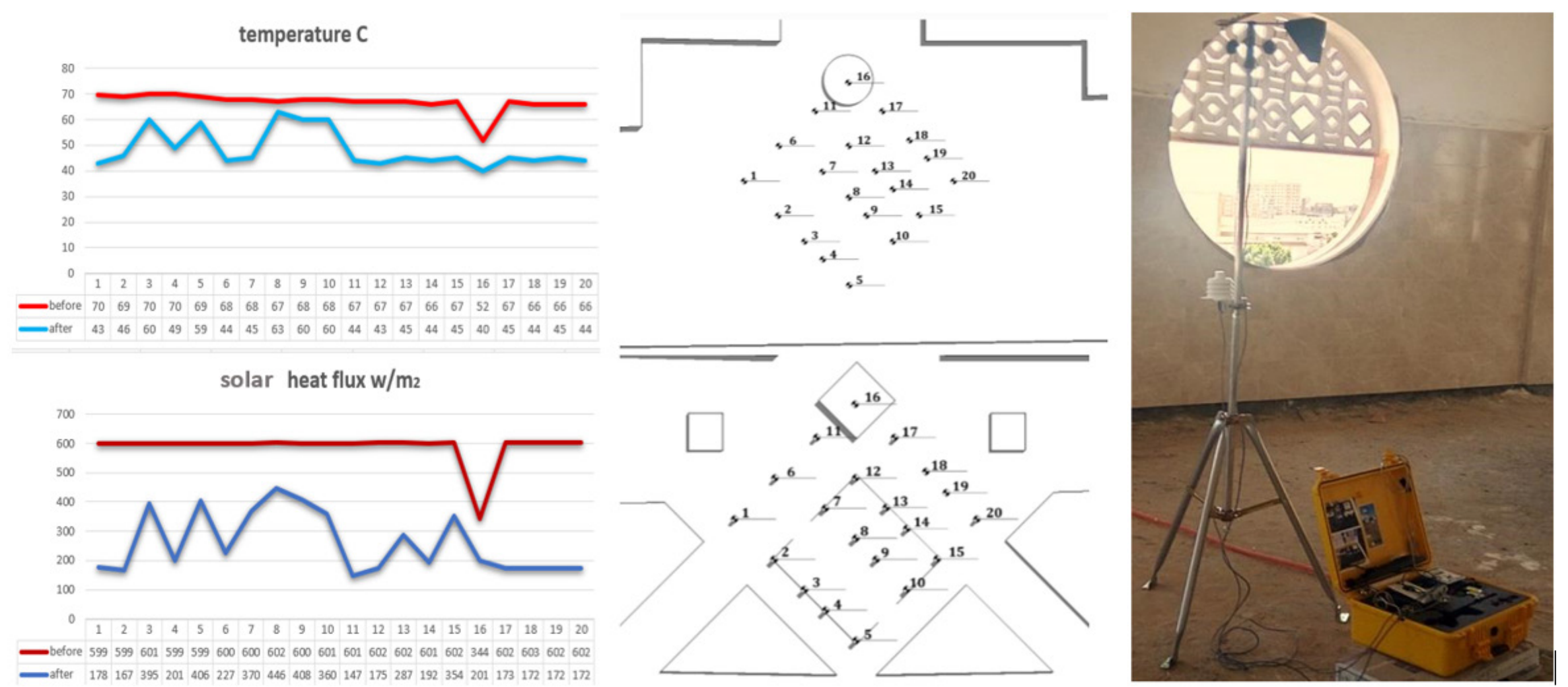

Figure 4. Measurements of the selected 20 monitoring points at $\operatorname{COS}$ on the left, and at the right-side Field measurement equipment Nova- Lynx weather station. (Source: Authors). 
In the middle of the square, four wooden pergolas were added to create semi-closed social activity shaded areas. Also, two fountains were installed for noise depletion reinforcing a stress-free atmosphere, besides its cooling effect decreasing surrounding temperature[10]. Fig.5 displayed different COS landscape characteristics that succeeded in enhancing microclimate urban environments; as exposed in fig.5, the COS landscape design was developed in order to resolve some problems hindering the use of external spaces such as excessive solar radiation and high air temperature[11]. Also, the new design made an Environmental positive contribution to urban by creating new open and green spaces schemes.

\section{Materials and Methods}

The master plan of the campus was utilized as study material. Google and researchers' photos, as well as digital tools like Adobe Photoshop, were utilized for COS visualization and studies.

Firstly, the current situation of the environmental conditions of the COS was analyzed through using the Climate Consultant6.0 program[12, 13] and Nova- Lynx WS-25 data logger weather station for field measurements [14], investigations revealed excessive solar radiation and high temperature hampering using overlooked space between buildings.

The proposed design was developed to enhance the environmental performance of the COS which was tested and evaluated with simulation tools to study its performance before and after the new design implementation. Numerical simulation was carried out using the Ansys Fluent CFD software [15, 16]. The impact of the new design was surveyed by comparing contours of solar heat flux, reflected infrared solar flux [17], wall temperature of surrounding surfaces, and Analyzing the air temperature before and after implementation, as shown in figure 4 and figure 6 .

\subsection{Field Measurement Method}

Field measurements were obtained by using Ws-25 data loggers in $\operatorname{COS}$ the field measurements equipment, as shown in fig. 4, attentive to trace air temperature and solar radiation. These measurements played two main roles in the study. It acts as input independent variables and controlling analysis for validation.

\subsection{The Computational Fluid Dynamics Method}

The Computational Fluid Dynamics (CFD) method is based on field measurement and weather information as Data input for the COS simulation method. The main advantage of using CFD is that it can swiftly predict future design scenarios based on solid-based input data and analyzing the environmental performance of the implemented design [18].

The data was investigated at a fixed time such as 21 September at $2.00 \mathrm{pm}$ through the study period due to Momentary weather changes, the selected COS was divided with 20 monitoring points distributed in grid distribution with grid different sizes. The results due to implemented design were showing a remarkable decrease in air temperature and radiated heat flux after design modification. Point 1 shows the maximum decrease while point 8 shows the minimum decrease of values, as shown in fig 4.

The five main processes of Ansys Fluent simulation begin with creating a geometrical model using available data and drawings, we used AutoCAD in the current study to build a three-dimensional model. Secondly, the grid cell generation process. The third stage focused on setting up the surrounding boundary conditions which identify the surrounding buildings, surfaces, and needed measuring points. Fourthly, the iteration process using energy equation, radiation-Rosseland model, solar loading and the turbulent kinetic energy $\mathrm{k}$ method is represented in the following equations [15, 19-23]:

$$
\begin{gathered}
\frac{\partial(p k)}{\partial t}+\frac{\partial\left(p k u_{i}\right)}{\partial x_{i}}=\frac{\partial}{\partial x_{i}}\left[\frac{\mu_{t}}{\sigma k} \frac{\partial k}{\partial x_{j}}\right]+2 \mu_{t} E_{i j} E_{i j}-p \varepsilon \\
\frac{\partial(p k)}{\partial t}+\frac{\partial\left(p \varepsilon u_{i}\right)}{\partial x_{i}}=\frac{\partial}{\partial x_{i}}\left[\frac{\mu_{t}}{\sigma \varepsilon} \frac{\partial \varepsilon}{\partial x_{j}}\right]+C_{1 \varepsilon} 2 \mu_{t} E_{i j} E_{i j} \\
-C_{2 \varepsilon} p \frac{\varepsilon^{2}}{k}
\end{gathered}
$$

For dissipation $\varepsilon$ k: Ui represents in the appropriate direction the velocity component

$\mathrm{Eij}$ is the deformation rate component.

$\mu \mathrm{t}$ is eddy viscosity [14, 24-26]: External Radiation and Heat flux to walls and COS surfaces is calculated in ANSYS

FLUENT according to this equation:

$$
\begin{gathered}
q=h_{f}\left(T_{w}-T_{f}\right)+q_{\text {rad }} \\
=h_{\text {ext }}\left(T_{\text {ext }}-T_{w}\right)+\varepsilon_{\text {ext }} \sigma\left(T_{\infty}{ }^{4}-T_{w}{ }^{4}\right) \\
\varepsilon_{e x t}=\text { External surface wall emissivity } \\
\sigma=\text { The constant of Stefan-Boltzmann } \\
T_{w}=\text { Surface wall temperature } \\
T_{\infty}=\text { Radiation source temperature }
\end{gathered}
$$

$q_{\text {rad }}=$ Wall heat flow from the radiative domain

Combined External Convection and Radiation equation $[25,26]$

$$
\begin{aligned}
q & =h_{f}\left(T_{w}-T_{f}\right)+q_{\text {rad }} \\
& =\varepsilon_{\text {ext }} \sigma\left(T_{\infty}^{4}-T_{w}^{4}\right)
\end{aligned}
$$


Heat flux calculated on the surface of model objects $q_{d}$ According to this equation:

$$
q_{d}=-k \nabla t \cdot n \rightarrow
$$

Where $\mathrm{k}$ represents material conductivity, and $\mathrm{T}$ represents temperature, and $n \rightarrow$ is normal to the surface. [11, 19, 27-29]

Finally, data interpretation and analyzing graphs were generated as the last stage to clarify the results obtained as shown in figure 6. Boundary conditions of the COS are traced from the surrounding Engineering faculty buildings to be set up in the processing stage. The simulations performed with the surrounding buildings within the campus were modelled explicitly and the outer buildings of the campus were modelled implicitly by including its properties within the inlet boundary conditions in the processing stage. The velocity profile of the inlet wind speed was used as an inlet boundary condition[30].

Field measurements are developed to trace parameters before and after implementation such as solar heat flux, reflected infrared solar flux, wall radiated heat flux of surrounding buildings, and Analysis of temperature [23, 31, 32] as shown in figure 7.

\section{Results}

Climatic conditions in Seberbay Campus are detected from Tanta weather station and interpreted through climate consultant 6.0, which are shown in Fig5. Inspecting the data revealed the Environmental potentials of the Seberbay Campus' open space redesign.

First comparing these conditions with the ASHRAE Handbook 2005 Determinants that people dressed in normal winter clothes, the comfort temperatures is 680 $\mathrm{F} 0(20.00 \mathrm{C} 0)$ to $740 \mathrm{~F} 0(23.30 \mathrm{C} 0)$ at relative humidity $50 \%$ [33], the comfort upper-temperature value could shift 50 F0 (2.80 C0) warmer If lightweight summer clothes were dressed up, ASHRAE will also indicate if the global horizontal radiation value exceeded $315.5 \mathrm{wh} / \mathrm{m}^{2}$. There is a need for shading, as shown in Fig 5.

Comparison of the COS before and after the redesign as shown in fig. 6 demonstrate results that indicate a decrease in surface temperature from 70 Celsius to 44 Celsius, global horizontal radiation from $650 \mathrm{Wh} / \mathrm{m}^{2}$ to $150 \mathrm{Wh} / \mathrm{m}^{2}$, and the air temperature decreased by 15 Celsius from $50 \mathrm{c} 0$ to $35 \mathrm{c} 0$. These results are important for many reasons including the prosperity in the selected places of the newly installed shades like pergolas and the new greenery in the plaza, taking into consideration human comfort. 


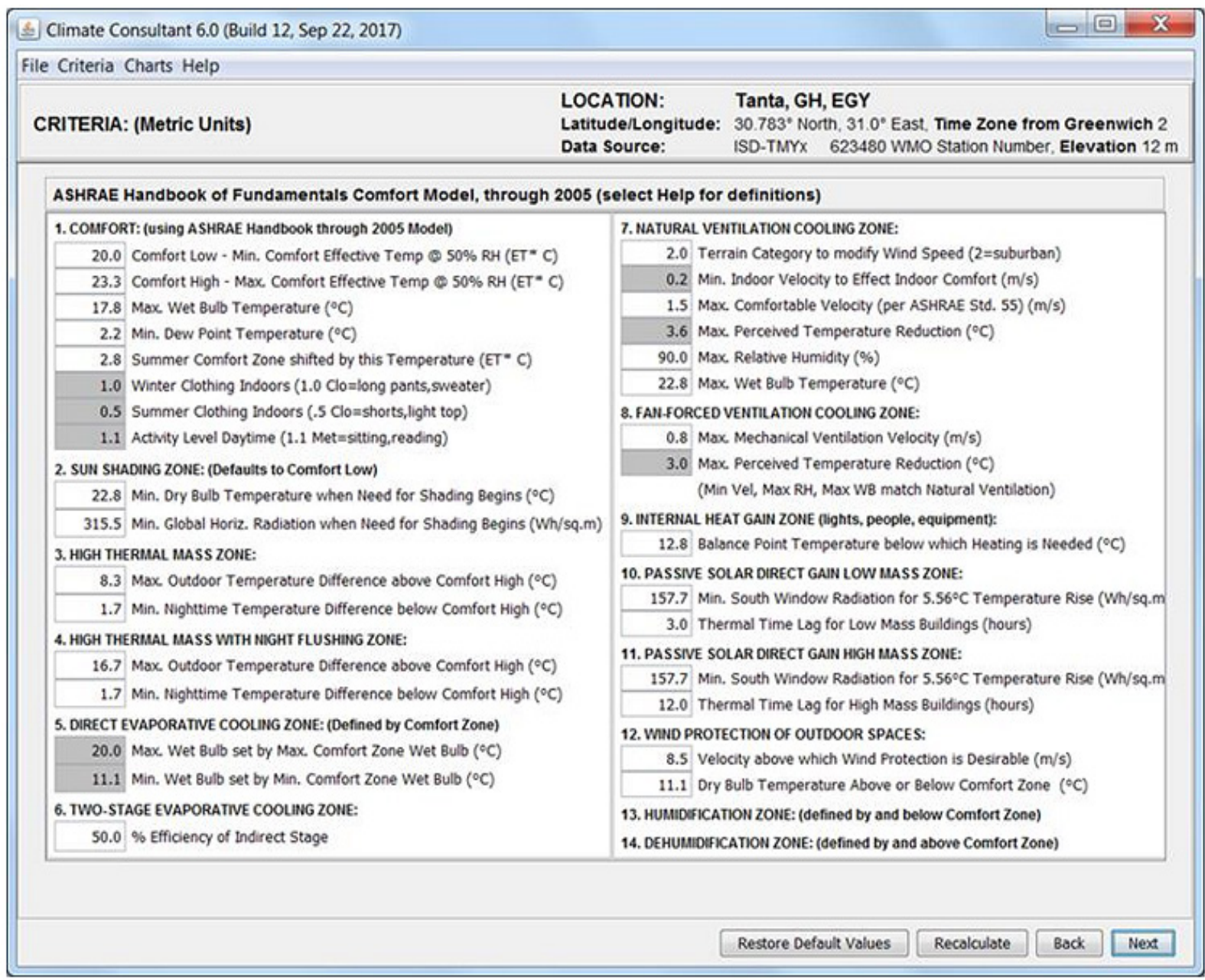
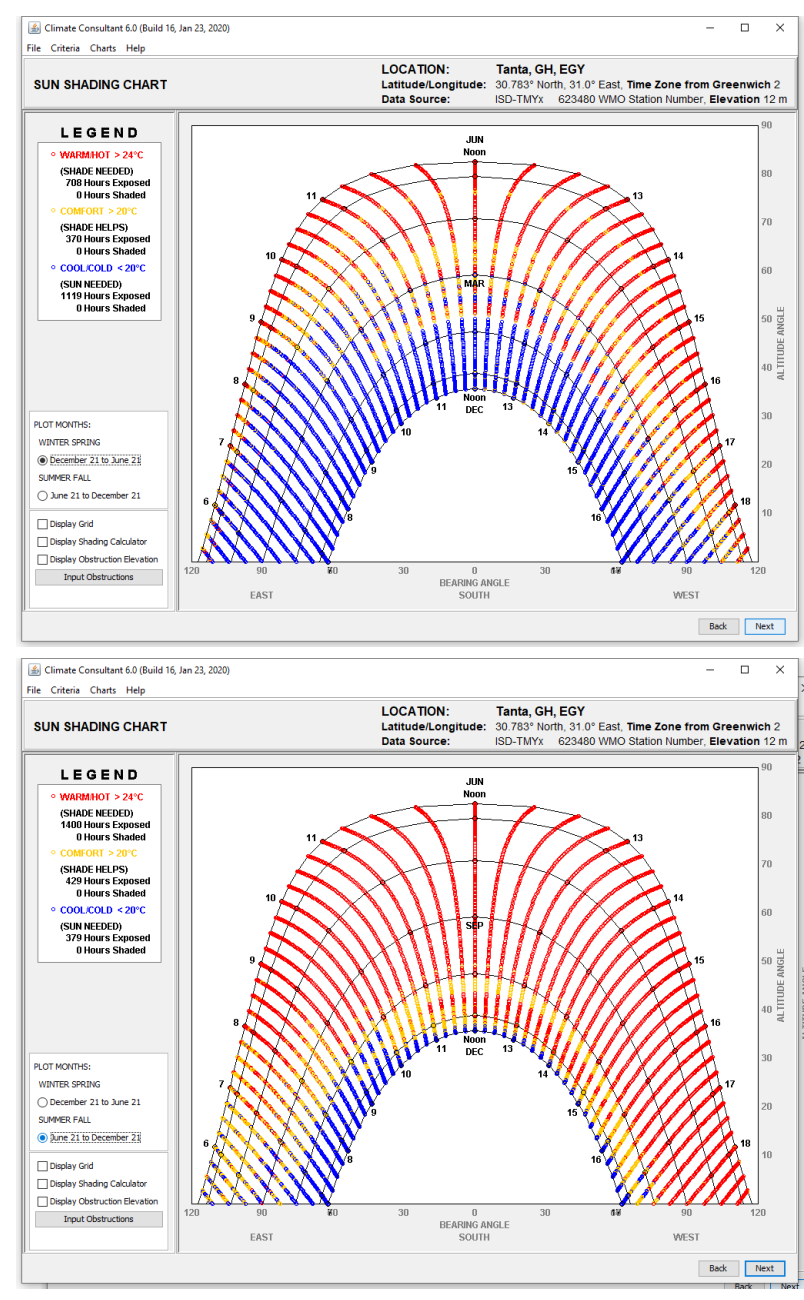

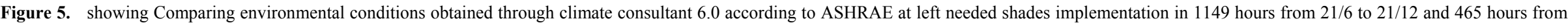
$21 / 6$ to $21 / 12$ at right 

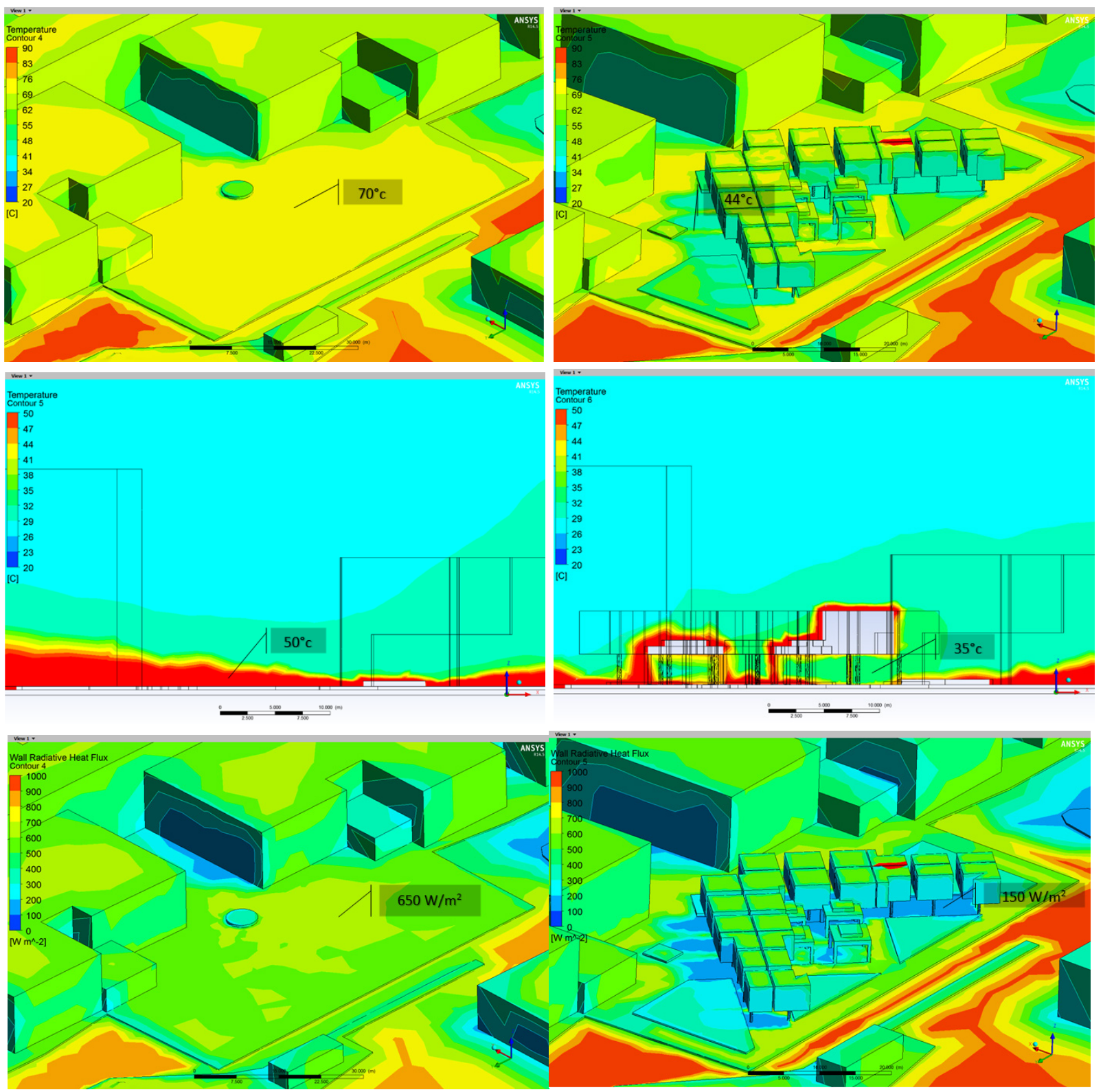

Figure 6. Comparison A revealed that Floor Surfaces Temperature decreased from 70 Celsius to 44 Celsius at 2.00 pm measured on 21 September, and Comparison B between global horizontal radiation value before the implementation of the retrofitting of the COS which exceeded $315.5 \mathrm{wh} / \mathrm{m}^{2}$ and then after redesigning as global horizontal radiation increased especially in shaded zones.

Also, Fig. 6 proves the positive impact of the COS in diminishing needs of shades, by comparing global horizontal radiation values before and after implementation. The comparison revealed that global horizontal radiation value before the implementation of the retrofitting of the $\operatorname{COS}$ which exceeded $315.5 \mathrm{wh} / \mathrm{m}^{2}$ up to $650 \mathrm{wh} / \mathrm{m}^{2}$ and, after redesigning as global horizontal radiation increased especially in shaded zones to $150 \mathrm{wh} / \mathrm{m}^{2}$.

After the COS design retrofitting, floor Surfaces Temperature decreased from 70 Celsius to 44 Celsius at $2.00 \mathrm{pm}$ measured on 21 September as shown in Fig.6. Moreover, these readings reassure the positive impact of the presence of the shaded devices either green trees or wooden pergolas in minimizing floor surface temperature, especially in shaded areas.

\section{Discussions}

According to Figure7 on the top, the isometric view and the graph show the vast variance between the two cases. The first initial case showed a low fluctuation range of absorbed solar heat flux ranges between urban surfaces especially on ground surfaces. All values decreased, especially in shaded areas, as shown in Figures 6 and 7. The proposed urban structures added in the modified case resulted in improving values of absolute solar heat flux ranges which obviously when exceeded can lead to 
discomfort thermal conditions.

According to the next Figure 7 in the middle, the isometric view and the graph show the vast variance between the two cases. The first initial case showed a low fluctuation range of reflected IR solar flux ranges between urban surfaces especially on ground surfaces. The proposed urban structures added in the modified case resulted in enhancing values of reflected IR solar flux ranges in which its increase causes discomfort thermal conditions.

Using different materials and adding green areas resulted in decreasing absorbed visible solar flux and enhancing thermal comfort, as shown in the bottom of Fig. 7.

These results are important for many reasons as they revealed new methods of assessing the retrofitting design of Campus Outer Spaces (COS) which took into consideration environmental conditions and surrounding boundaries. The obtained results also support retrofitting design decisions either in greenery or installing pergolas or used surface finishing materials or water elements instalment. Also, comparison between status before and after implementation approved COS retrofitting design success in creating diverse spaces to encompass different purposes.

According to AHRAE, standards of human comfort and environmental needs showing the need for shading when global horizontal radiation value exceeded $315.5 \mathrm{wh} / \mathrm{m}^{2}$, and the upper value of Maximum comfort high temperature is $26.1^{\circ} \mathrm{C}$ If lightweight summer clothes were dressed.

Monitoring the environmental performance of the COS through measurements or using simulation programs led to the emergence of problems that hinder the use of COS spaces. The surface temperature was up to 70 degrees Celsius, and the air temperature reached 50 degrees Celsius before retrofitting the COS

As for the implementation of the proposed design, the environmental performance of the campus improved, as the surface temperature in the shade decreased to 44 degrees Celsius; and consequently, the air temperature decreased to 35 degrees Celsius, as a result of avoiding excess solar radiation by using the shading methods described in the concept design, where the solar radiation decreased to a comfortable value $150 \mathrm{w} / \mathrm{m}^{2}$ according to AShARE which enhanced the thermal performance of the studied COS by decreasing the air temperature by 15 Celsius, surface temperature by 26 Celsius, and $500 \mathrm{w} / \mathrm{m}^{2}$ of solar radiation value.

Using the simulation program Ansys fluent in evaluating the new design enables us to make a more profound analysis of many factors affecting the environmental performance. As shown at the top of Figure 7, the absorbed infrared solar flux diagram reveals a decrease of $203 \mathrm{w} / \mathrm{m}^{2}$ from 290 to $87 \mathrm{w} / \mathrm{m}^{2}$ in, as well as a decrease in the infrared reflected flux. As shown in the middle diagram of $50 \mathrm{w} / \mathrm{m}^{2}$ from 71 to $21 \mathrm{w} / \mathrm{m}^{2}$, which directly affects the reduction of the heat loads of the spaces. Moreover, the reduction of visible radiation absorbed, from 480 to $180 \mathrm{w} / \mathrm{m}^{2}$ is shown in the last diagram which demonstrates a decrease of the temperature of the surfaces and the air in contact with those surfaces. Also, avoiding heat and excessive radiation and improving thermal comfort are apparent results of reducing all these values. 

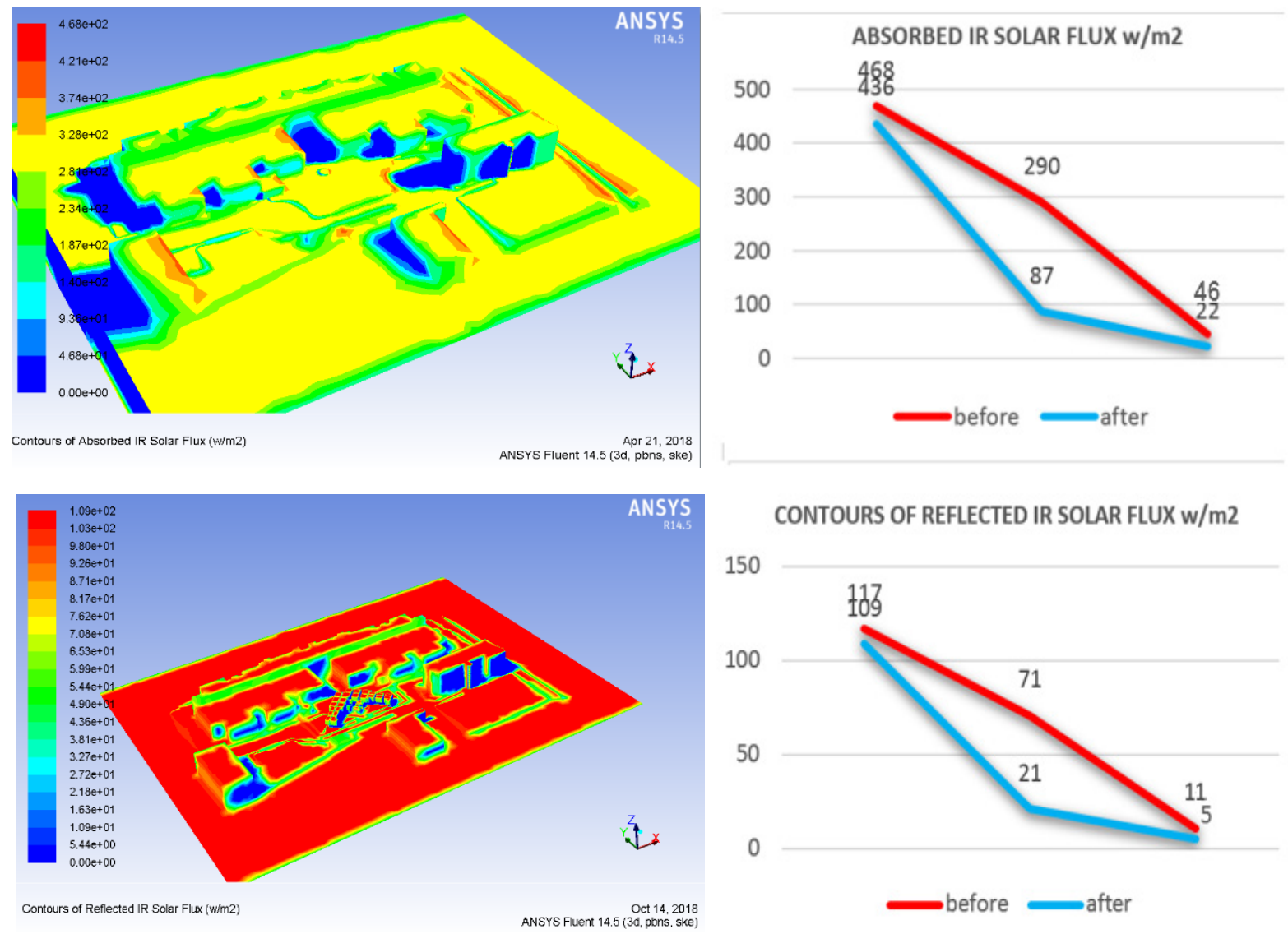

\section{CONTOURS OF REFLECTED IR SOLAR FLUX w/m2}
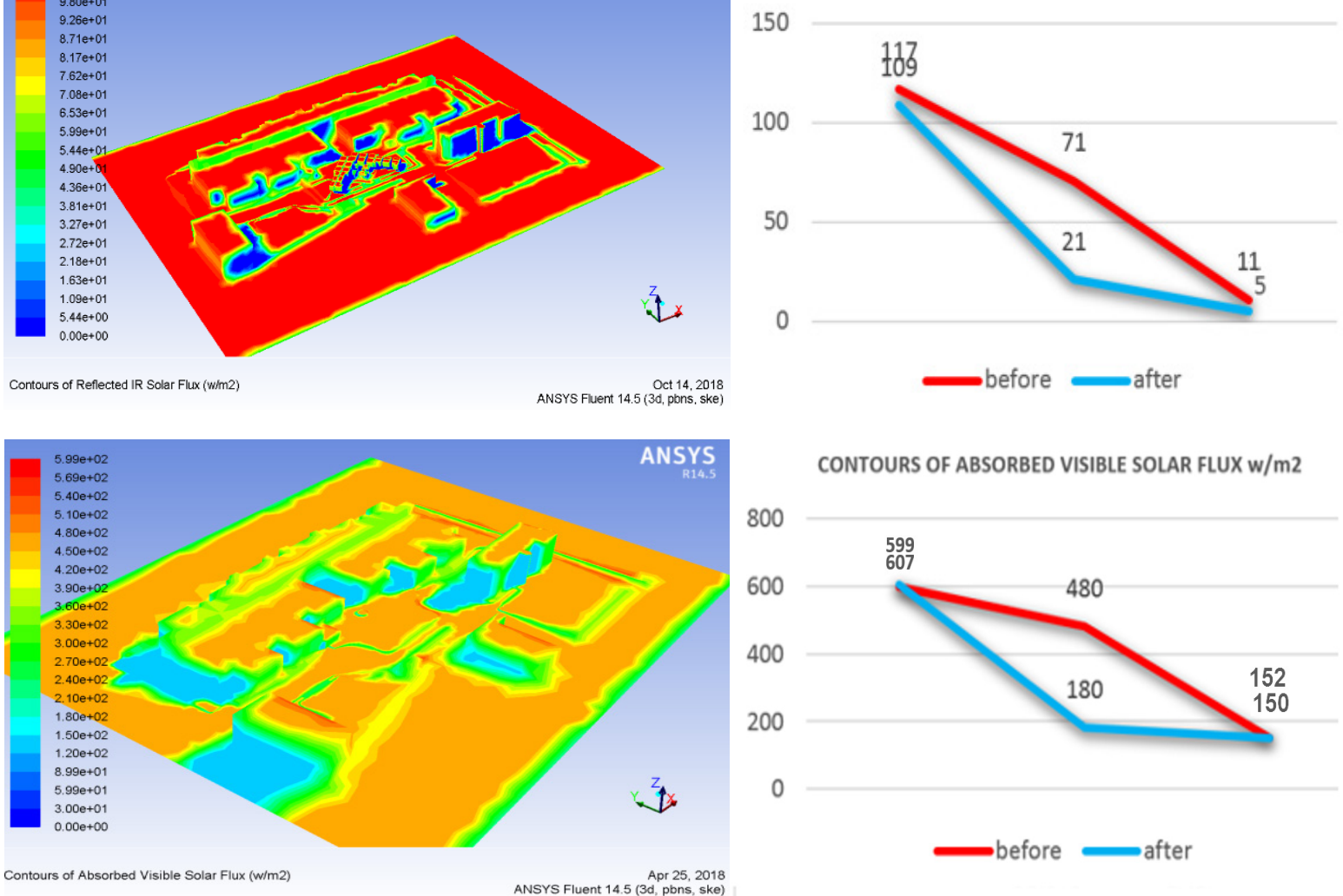

CONTOURS OF ABSORBED VISIBLE SOLAR FLUX w/m2

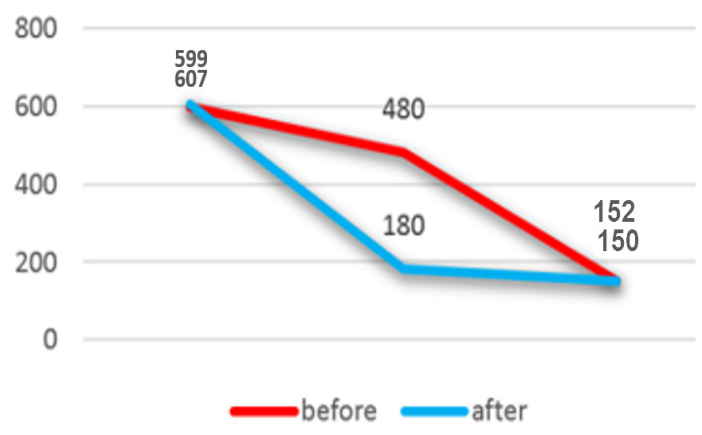

Figure 7. shows on top contours of absorbed IR solar flux, in the middle contours of reflected IR solar flux, and at the bottom contours of absorbed visible solar flux.

\section{Conclusions}

The main concept of retrofitting design of Seberbay campus Outdoor Space (COS) focused on providing a healthy warm environment, physical comfort and relaxing greener sceneries. Analyzing existing problems in the COS and developing a vision that overcomes these problems was the main target of the COS retrofitting research and design.

The major findings of this study are related to the ability to numerically assess features that affect the urban quality and assess project developed thermal performance after retrofitting of the selected COS. For example, the use of shading design elements enhanced the thermal performance of the studied COS by the air temperature by 15 Celsius, surface temperature 26 Celsius and $500 \mathrm{w} / \mathrm{m}^{2}$ of solar radiation value.

The importance of the environmental approach in the proposed retrofit of the COS was authenticated through the assessment of the design decisions technically. This research specified successful design strategies for Campus Outdoor spaces to achieve A healthy, vibrant and sustainable environment for optimal use of space. Also, it represents technical ways of qualitative evaluation of the 
renovating proposal.

\section{REFERENCES}

[1] Atilla, K. G. Ü. L., E., \& UZUN, Ö. F. (2016). Recreational Demand and Trends, S. in the Campus Students and Lecturers of Süleyman Demirel University, Demirel University Journal of Architecture Sciences and Applications, and -. A. G. 2016, E. Keles, O. F. Uzun, https://doi.org/10.30785/mbud.282560, ed.

[2] R. H. Penner, Adams, L., \& Rutes, W. (2012). Hotel Design, Planning and Development (2nd ed.). Routledge. https://doi.org/10.4324/9780080967004, ed.

[3] P. A. [Mathias Loki, Christine Majale and Samuel Kigondu (2020) and M. C. THE TYPOLOGY OF PUBLIC OPEN SPACES: CLASSIFICATION AND CHALLENGES FROM MACHAKOS MUNICIPALITY, KENYA Int. J. of $A d v$. Res. 8 (Dec). 241-255] (ISSN 2320-5407). https://doi.org/10.21474/ijar01/12144, ed.

[4] Y1lmaz, G. T., D., Șavkl1, F., \& Çeşmecİ, S. (2012). A study on young disabled, p. s. u. o. c. a. i. t. u. c. e. o. Olbia, Culture Center in Akdeniz University. Journal of Tekirdag Agricultural Faculty, and -. 9(3), ed.

[5] S. S. Y. Lau, Z. Gou, and Y. Liu, "Healthy campus by open space design: Approaches and guidelines," Frontiers of Architectural Research, vol. 3, no. 4, pp. 452-467, 2014, doi: https://doi.org/10.1016/j.foar.2014.06.006.

[6] A. A. Bek MA, Ahsan A. Numerical simulation of the wind environment around, T. U. buildings: Case Study for Seberbay Campus, Egypt. Journal of Advanced Civil Engineering Practice, a. R. 2016, and 3:9-14, ed.

[7] K. G. Scholl and G. B. Gulwadi, "Recognizing campus landscapes as learning spaces," Journal of Learning Spaces, vol. 4, no. 1, pp. 53-60, 2015.

[8] F. A. Matloob, A. B. Sulaiman, T. H. Ali, S. Shamsuddin, and W. N. Mardyya, "Sustaining campuses through physical character-the role of landscape," Procedia-Social and Behavioral Sciences, vol. 140, pp. 282-290, 2014, doi: https://doi.org/10.1016/j.sbspro.2014.04.421.

[9] O. Yerli and S. Ozdede, "Design Process of a Campus Plan: A Case Study of Duzce University Konuralp Campus," International Journal of Engineering Research and Applications, vol. 07, no. 04, pp. 50-59, 2017-04-01 2017, doi: https://doi.org/10.9790/9622-0704015059.

[10] N. Kabisch, R. Kraemer, O. Masztalerz, J. Hemmerling, C. Püffel, and D. Haase, "Impact of summer heat on urban park visitation, perceived health and ecosystem service appreciation," Urban Forestry \& Urban Greening, vol. 60, p. 127058, 2021-05-01 2021, doi: https://doi.org/10.1016/j. ufug.2021.127058.

[11] J. K. Nayak, S. P. Sukhatme, R. G. Limaye, and S. V. Bopshetty, "Performance studies on solar concrete collectors," Solar Energy, vol. 42, no. 1, pp. 45-56, 1989-01-01 1989, doi: https://doi.org/10.1016/0038-092x( 89)90129-1.

[12] Z. Li, S. Wang, C. Dong, and Q. Zhang, "Climate
Adaptability Analysis of Dwellings in Eastern Hebei Province under Building Energy Efficiency Context," 2020, vol. 1624: IOP Publishing, 4 ed., p. 042048, doi: https://doi.org/10.1088/1742-6596/1624/4/042048.

[13] J. R. Zaniani, S. T. Ghahfarokhi, M. Jahangiri, and A. A. Shamsabadi, "Design and optimization of heating, cooling and lightening systems for a residential villa at Saman city, Iran," Journal of Engineering, Design and Technology, 2019, doi: https://doi.org/10.1108/jedt-01-2018-0003

[14] M. M. Elwan and H. A. Dewair, "Lattice windows as a natural ventilation strategy in hot, humid regions," in IOP Conference Series: Earth and Environmental Science, 2019, vol. 397, 1 ed., doi: https://doi.org/10.1088/1755-1315/397 $/ 1 / 012022$

[15] J. K. Calautit, B. R. Hughes, D. O'Connor, and S. S. Shahzad, "CFD and wind tunnel study of the performance of a multi-directional wind tower with heat transfer devices," Energy Procedia, vol. 75, pp. 1692-1697, 2015, doi: https://doi.org/10.1016/j.egypro.2015.07.425

[16] M. Hajdukiewicz, M. Geron, and M. M. Keane, "Calibrated CFD simulation to evaluate thermal comfort in a highly-glazed naturally ventilated room," Building and Environment, vol. 70, pp. 73-89, 2013/12/01/ 2013, doi: https://doi.org/10.1016/j.buildenv.2013.08.020.

[17] N. Mingotti, T. Chenvidyakarn, and A. W. Woods, "Combined impacts of climate and wall insulation on the energy benefit of an extra layer of glazing in the facade," Energy and Buildings, vol. 58, pp. 237-249, 2013-03-01 2013, doi: https://doi.org/10.1016/j.enbuild.2012.11.033.

[18] M. M. Elwan, "The role of traditional Lattice window "Mashrabiya" in delivering single-sided ventilation-A CFD study," SSRG International Journal of Engineering Trends and Technology, Article vol. 68, no. 9, pp. 154-161, 2020, doi: https://doi.org/10.14445/22315381/ijett-v68i9p221.

[19] E. M. Alawadhi, "Using phase change materials in window shutter to reduce the solar heat gain," Energy and Buildings, vol. 47, pp. 421-429, 2012, doi: https://doi.org/10.1016/j.enbuild.2011.12.009.

[20] J. K. Calautit, D. O'Connor, and B. R. Hughes, "Determining the optimum spacing and arrangement for commercial wind towers for ventilation performance," Building and environment, vol. 82, pp. 274-287, 2014, doi: https://doi.org/10.1016/j.buildenv.2014.08.024

[21] G. Evola and V. Popov, "Computational analysis of wind driven natural ventilation in buildings," Energy and buildings, vol. 38, no. 5, pp. 491-501, 2006, doi: https://doi.org/10.1016/j.enbuild.2005.08.008.

[22] B. E. Launder and B. I. Sharma, "Application of the energy-dissipation model of turbulence to the calculation of flow near a spinning disc," Letters in heat and mass transfer, vol. 1, no. 2, pp. 131-137, 1974, doi: https://doi.org/10.1016/0094-4548(74)90150-7

[23] C. Porras-Amores, F. R. Mazarrón, I. Cañas, and P. Villoría Sáez, "Natural ventilation analysis in an underground construction: CFD simulation and experimental validation," Tunnelling and Underground Space Technology, vol. 90, $\mathrm{pp}$ 162-173, 2019, doi: https://doi.org/10.1016/j.tust.2019.04. 023. 
[24] M.-F. King et al., "Investigating the influence of neighbouring structures on natural ventilation potential of a full-scale cubical building using time-dependent CFD," Journal of Wind Engineering and Industrial Aerodynamics, vol. 169, pp. 265-279, 2017, doi: https://doi.org/10.1016/j.jweia.2017.07.020

[25] J. Lien and N. Ahmed, "Wind driven ventilation for enhanced indoor air quality," in Chemistry, Emission control, Radioactive pollution and indoor air quality: IntechOpen, 2011.

[26] M. Shirzadi, Y. Tominaga, and P. A. Mirzaei, "Wind tunnel experiments on cross-ventilation flow of a generic sheltered building in urban areas," Building and Environment, vol. 158, pp. 60-72, 2019, doi: https://doi.org/10.1016/j.builden v.2019.04.057.

[27] L. de Oliveira Neves and F. M. da Silva, "Simulation and measurements of wind interference on a solar chimney performance," Journal of Wind Engineering and Industrial Aerodynamics, vol. 179, pp. 135-145, 2018, doi: https://doi.org/10.1016/j.jweia.2018.05.020.

[28] S. Hu, R. Zhu, R. Liu, K. Dong, and Z. Li, "Fluid-Solid Coupling Simulation on the Temperature Distribution of Tuyere Used for Oxygen Bottom Blowing Converter,"
Metallurgical and Materials Transactions B, vol. 49, no. 6, pp. 3317-3329, 2018, doi: https://doi.org/10.1007/s11663018-1375-8.

[29] J. Matsson, An Introduction to ANSYS Fluent 2020. SDC Publications, 2020.

[30] M. Taleghani, W. Swan, E. Johansson, and Y. Ji, "Urban cooling: Which façade orientation has the most impact on a microclimate?," Sustainable Cities and Society, vol. 64, p. 102547, 2021-01-01 2021, doi: https://doi.org/10.1016/j.sc s.2020.102547.

[31] J. Mi, B. Hong, T. Zhang, B. Huang, and J. Niu, "Outdoor thermal benchmarks and their application to climateresponsive designs of residential open spaces in a cold region of China," Building and Environment, vol. 169, p. 106592, 2020, doi: https://doi.org/10.1016/j.buildenv.2019 .106592 .

[32] S. Zeybekoglu Sadri, "City, Urban Transformation and the Right to the City," Journal of Contemporary Urban Affairs, vol. 4, no. 1, pp. 1-10, 2020-06-01 2020, doi: https://doi.org/10.25034/ijcua.2020.v4n1-1.

[33] O. Irulegi, "Tools and Strategies for Microclimatic Analysis of the Built Environment," in Energy Performance of Buildings: Springer, 2016, pp. 485-498. 